\title{
Daytime and night time motor activity of the small bowel after solid meals of different caloric value in
} humans

\author{
J v Schönfeld, D F Evans, D L Wingate
}

\begin{abstract}
Background-Meals disrupt the interdigestive pattern of small bowel motor activity and convert it into the postprandial pattern. Previous studies have shown that duration of postprandial motor activity depends on the caloric value of a meal, but results from two recent human studies suggested that there is a caloric ceiling, above which an additional increase in the caloric load fails to prolong the postprandial period further.
\end{abstract}

Aim-To investigate the hypothesis of a caloric ceiling by studying daytime motor activity of the human small bowel in response to five solid meals, covering a wide range of calories.

Methods-Eight healthy male volunteers underwent five separate, ambulatory small bowel manometry studies and had a total of 80 meals. For lunch, volunteers ate between one and five portions of a solid meal (220, $440,660,880$, or $1100 \mathrm{kcal})$. Ten hours later and 30 minutes before they went to bed, they ate either two or four portions of the same meal (440 kcal or $880 \mathrm{kcal})$. Recordings were analysed visually for phase III of the migrating motor complex and a validated computer program calculated incidence and amplitude of contractions.

Results-Apart from two versus three portions (440 kcal $v 660 \mathrm{kcal}$ ), postprandial motor activity was significantly prolonged by each $220 \mathrm{kcal}$ increase in the caloric load of the lunch (168 (SEM 14), 305 (22), 298 (23), 368 (36), and 398 (38) min). Mean incidence of contractions was significantly different only between the two extremes tested: $220 \mathrm{kcal}$ and $1100 \mathrm{kcal}(2.9(0.3) v$ $\left.4 \cdot 5(0 \cdot 6) \mathrm{min}^{-1}\right)$. Amplitude of contractions did not depend on meal size. Daytime and night time postprandial activity were not significantly different. This was true for duration of fed activity, as well as mean incidence and amplitude of contractions during the postprandial period.

Conclusion-Caloric value of a meal regulates duration of the fed activity in the human small bowel over a wide range of calories, and-for caloric loads up to 1100 kcal-there is no maximum duration of postprandial motor activity. Furthermore the postprandial small bowel motor activity is very similar between daytime and night time.

(Gut 1997; 40: 614-618)

Keywords: human, small bowel, postprandial, motility.
Two distinct motor patterns have been described in the canine and the human small bowel. Mainly for technical reasons, over the past two decades research has strongly focused on the interdigestive pattern, but recent advances in recording techniques and data analysis now allow the study of postprandial contractile activity. Motor activity of the small bowel can now be recorded in ambulatory subjects for prolonged periods, a prerequisite for detailed analysis of total postprandial motility, and computer programs have been validated that analyse pressure recordings objectively and rapidly. ${ }^{12}$

There are very few studies on postprandial motility, and almost all of these have been performed in strictly controlled animal physiology laboratories. In dogs, Schang et al and de Wever et al have shown that duration of postprandial motor activity depends on the caloric value of a meal. ${ }^{3}$ In humans, Ouyang et $a l$ and our group have shown the same phenomenon for liquid and solid meals, ${ }^{56}$ whereas Soffer and Adrian were recently unable to show a longer postprandial pattern after ingestion of higher caloric loads. ${ }^{7}$

The discrepancies between the three human studies $^{5-7}$ could be reconciled by postulating a caloric ceiling above which an additional increase in the caloric load does not further prolong duration of postprandial motor activity. We therefore investigated daytime motor activity of the human small bowel in response to five solid meals, covering a wide range of calories. As volunteers had the same meals for lunch and as a late night dinner, we were also able to compare daytime and night time contractile activity. A previous study from our group showed that the postprandial interval is shorter during sleep, suggesting that activity of the central nervous system regulates not only interdigestive but also postprandial motility of the small bowel.

Using 24 hour ambulatory manometry for data acquisition and a validated computer program for data analysis, we measured duration of the postprandial motor pattern, and also calculated incidence and amplitude of contractions over the total postprandial period. These data on postprandial motor motility of the normal human small bowel could serve as a basis for further research on intestinal disorders. ${ }^{89}$

\section{Methods}

SUBJECTS

Eight male healthy volunteers (mean age 26; range 19-38 years) participated in this study 
after written informed consent was obtained. None of them had a history of gastrointestinal disease or intra-abdominal surgery other than appendicectomy. No volunteer was on intercurrent medication or complained about abdominal symptoms. Volunteers were recruited

TABLE I Allocation of meals between the five studies

\begin{tabular}{lcl}
\hline Study & $\begin{array}{l}\text { Lunch } \\
\text { (kcal) }\end{array}$ & $\begin{array}{l}\text { Dinner } \\
\text { (kcal) }\end{array}$ \\
\hline 1 & 220 & 220 \\
2 & 440 & 440 \\
3 & 660 & 220 \\
4 & 880 & 440 \\
5 & 1100 & 220 \\
\hline
\end{tabular}

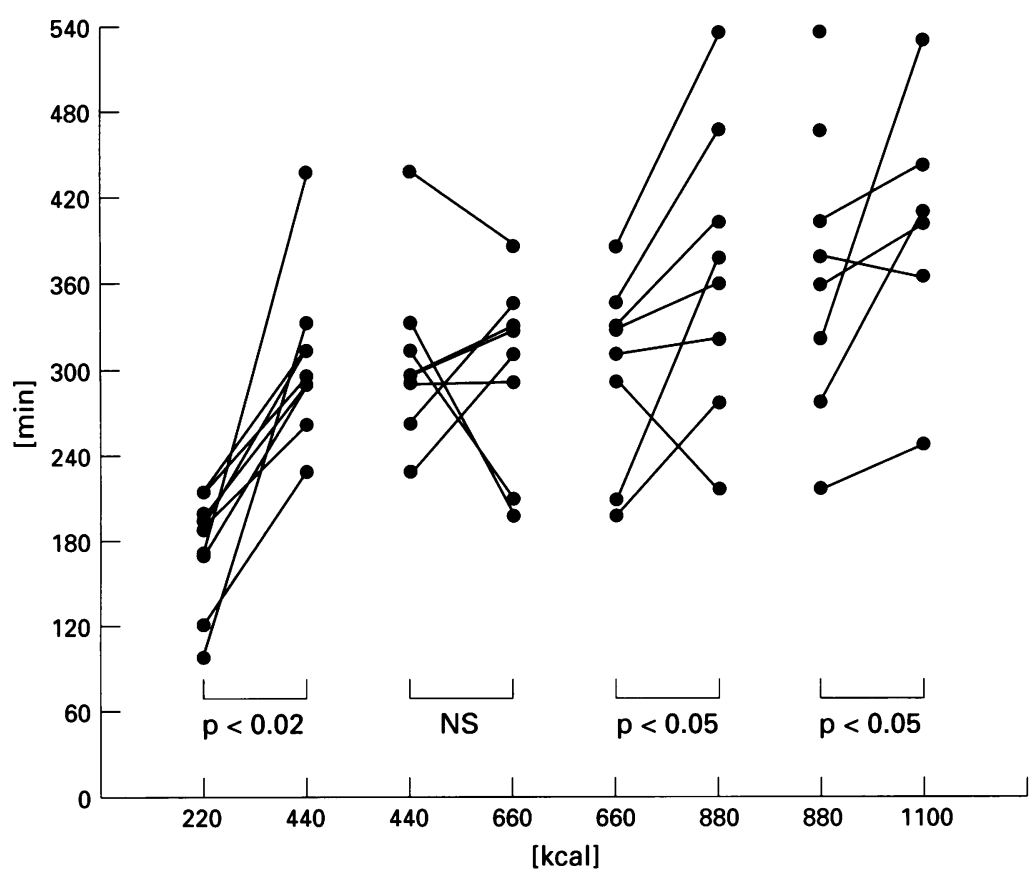

Figure 1: Duration of postprandial motor activity in the human jejunum after ingestion of one to five portions of a solid meal (220 kcal to $1100 \mathrm{kcal})$ during daytime.

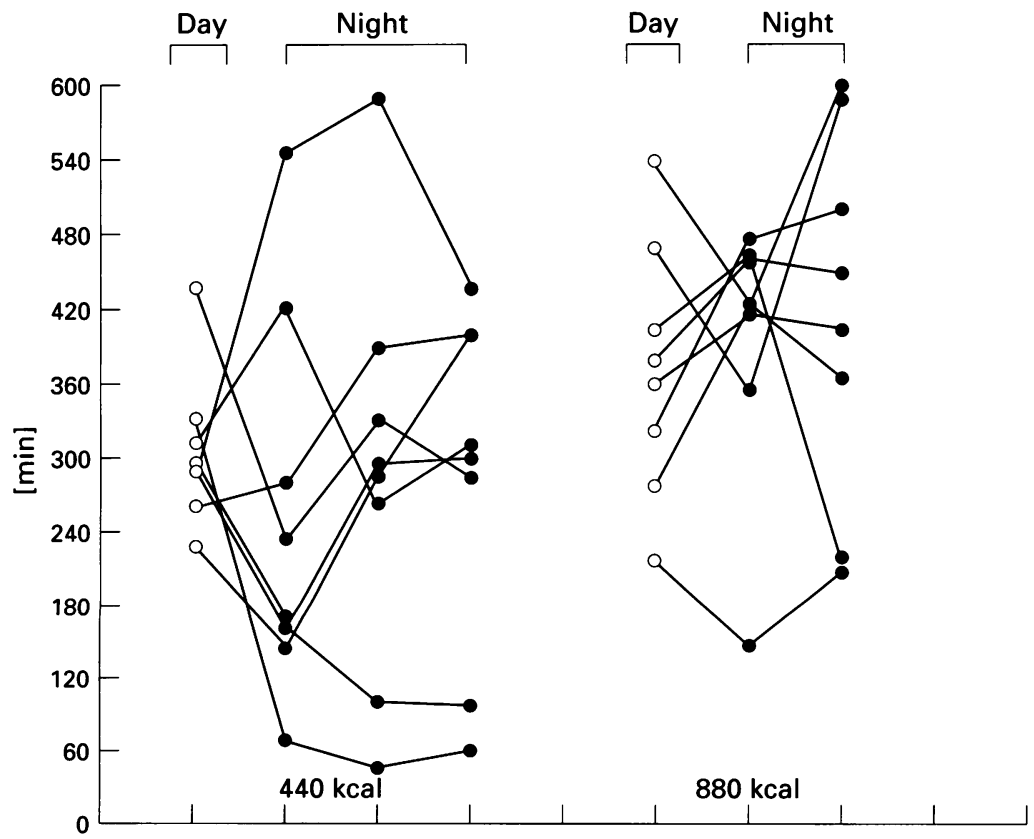

Figure 2: Duration of postprandial motor activity in the human jejunum after ingestion of two or four portions of a solid meal (440 kcal or $880 \mathrm{kcal}$ ) as a lunch or a late night dinner. Both two and four portions were only eaten once for lunch (open circles, daytime), but twice or three times as a late dinner (closed circles, night time). from the general population by word of mouth, and no volunteer was a member of staff. All volunteers had previously participated in similar research studies.

EXPERIMENTAL DESIGN

Within four weeks, subjects underwent five separate ambulatory manometry studies in a randomised order as described previously. ${ }^{10}$ On each of the five study days, after an overnight fast, a fine nasojejunal catheter with an outer diameter of $2.5 \mathrm{~mm}$ was positioned fluoroscopically, $30 \mathrm{~cm}$ distal to the Ligament of Treitz. Three strain gauge pressure sensors were incorporated 3,15 , and $45 \mathrm{~cm}$ from the tip of the catheter (Gaeltec, Dunvegan, Isle of Skye, UK). A lightweight portable solid state data logger (Cavendish Automation, St Neots, Beds, UK) was used for data acquisition at a sampling frequency of $2 \mathrm{~Hz}$. Once the catheter was in position, usually around midday, volunteers were allowed to leave the unit and they returned at the end of an experiment the next day. All volunteers kept a diary during the five studies. Sixty minutes after the recording was started, usually around $100 \mathrm{pm}$, volunteers ate between one and five portions of a palatable solid meal (tagliatelle with vegetables, Sainsbury, London). Each portion had $220 \mathrm{kcal}$, with $10 \%$ protein, $57 \%$ carbohydrates, and $33 \%$ fat. Volunteers drank 500 $\mathrm{ml}$ mineral water (Caledonian mineral water, Sainsbury, London) with their lunch. Most of the volunteers chose to eat their lunch in our unit. Ten hours after lunch and 30 minutes before they went to bed, volunteers had a late dinner. This consisted of either two or four portions of the same pasta meal. Volunteers also drank $500 \mathrm{ml}$ Caledonian mineral water with their late meal. During the study, volunteers were not allowed food or drinks other than the two meals, which were provided by us. Table I shows the allocation of the different meals within the five studies. The study was approved by the local ethics committee of Tower Hamlets District Health Authority.

DATA HANDLING AND ANALYSIS

Pressure data were downloaded from the data logger to an IBM compatible PC. Data from the middle sensor, placed at the Ligament of Treitz, were analysed. Visually we measured the period between start of ingestion of a meal and the appearance of the next phase III of the migrating motor complex. A phase III was ignored, if it occurred within 20 minutes after the start of the ingestion of a meal, as conversion of interdigestive to postprandial motor pattern is not necessarily an immediate process. ${ }^{11} 12 \mathrm{~A}$ validated computer program calculated incidence and amplitude of contractions, as described recently. ${ }^{2}$ These calculations were done both for the total period between start of ingestion and the appearance of the next phase III and for consecutive 30 minute periods.

Data are given either as individual data points or as mean (SEM). Data were compared 
TABLE II Duration of postprandial motor activity, mean incidence and amplitude of contractions as well as mean area under the curve within the postprandial period

\begin{tabular}{|c|c|c|c|c|c|}
\hline Study & 1 & 2 & 3 & 4 & 5 \\
\hline $\begin{array}{l}\text { Lunch (kcal) } \\
\text { Duration (min) } \\
\left.\text { Incidence (min }{ }^{-1}\right) \\
\text { Amplitude }\left(\mathrm{mm} \mathrm{Hg}^{\mathrm{H}}\right) \\
\text { Area under the curve } \\
\left(\mathrm{mm} \mathrm{Hg} \times \mathbf{s} \times \mathrm{min}^{-1}\right)\end{array}$ & $\begin{array}{l}220 \\
168(14) \\
2 \cdot 9(0 \cdot 3) \\
20 \cdot 9(0 \cdot 5) \\
206(16)\end{array}$ & $\begin{array}{l}440 \\
305(22) \\
3 \cdot 4(0 \cdot 7) \\
21 \cdot 3(1 \cdot 1) \\
238(54)\end{array}$ & $\begin{array}{l}660 \\
298(23) \\
3 \cdot 7(0 \cdot 4) \\
19 \cdot 3(0 \cdot 6) \\
236(27)\end{array}$ & $\begin{array}{l}880 \\
368(36) \\
3.3(0.5) \\
19 \cdot 3(0.5) \\
208(34)\end{array}$ & $\begin{array}{l}1100 \\
398(38) \\
4 \cdot 5(0 \cdot 6) \\
20 \cdot 1(0 \cdot 7) \\
302(43)\end{array}$ \\
\hline $\begin{array}{l}\text { Dinner (kcal) } \\
\text { Duration (min) } \\
\text { Incidence }\left(\mathrm{min}^{-1}\right) \\
\text { Amplitude }(\mathrm{mm} \mathrm{Hg}) \\
\text { Area under the curve } \\
\left(\mathrm{mm} \mathrm{Hg} \times \mathrm{s} \times \mathrm{min}^{-1}\right)\end{array}$ & $\begin{array}{l}440 \\
253(56) \\
2 \cdot 5(0 \cdot 5) \\
21 \cdot 0(0 \cdot 8) \\
172(37)\end{array}$ & $\begin{array}{l}880 \\
392(38) \\
2 \cdot 8(0 \cdot 6) \\
20 \cdot 2(0 \cdot 7) \\
195(44)\end{array}$ & $\begin{array}{l}440 \\
286(59) \\
2 \cdot 7(0 \cdot 4) \\
21 \cdot 5(0 \cdot 7) \\
169(27)\end{array}$ & $\begin{array}{l}880 \\
408(60) \\
2 \cdot 8(0 \cdot 6) \\
21 \cdot 5(1 \cdot 2) \\
179(43)\end{array}$ & $\begin{array}{l}440 \\
266(63) \\
2 \cdot 7(0 \cdot 5) \\
19 \cdot 9(0 \cdot 9) \\
185(37)\end{array}$ \\
\hline
\end{tabular}

using the Wilcoxon signed rank test. $P$ values $<0.05$ were considered significant.

\section{Results}

All volunteers completed the five studies, but two volunteers were unable to eat five portions $(1100 \mathrm{kcal})$ for lunch. A phase III was seen in all experiments after lunch and dinner.
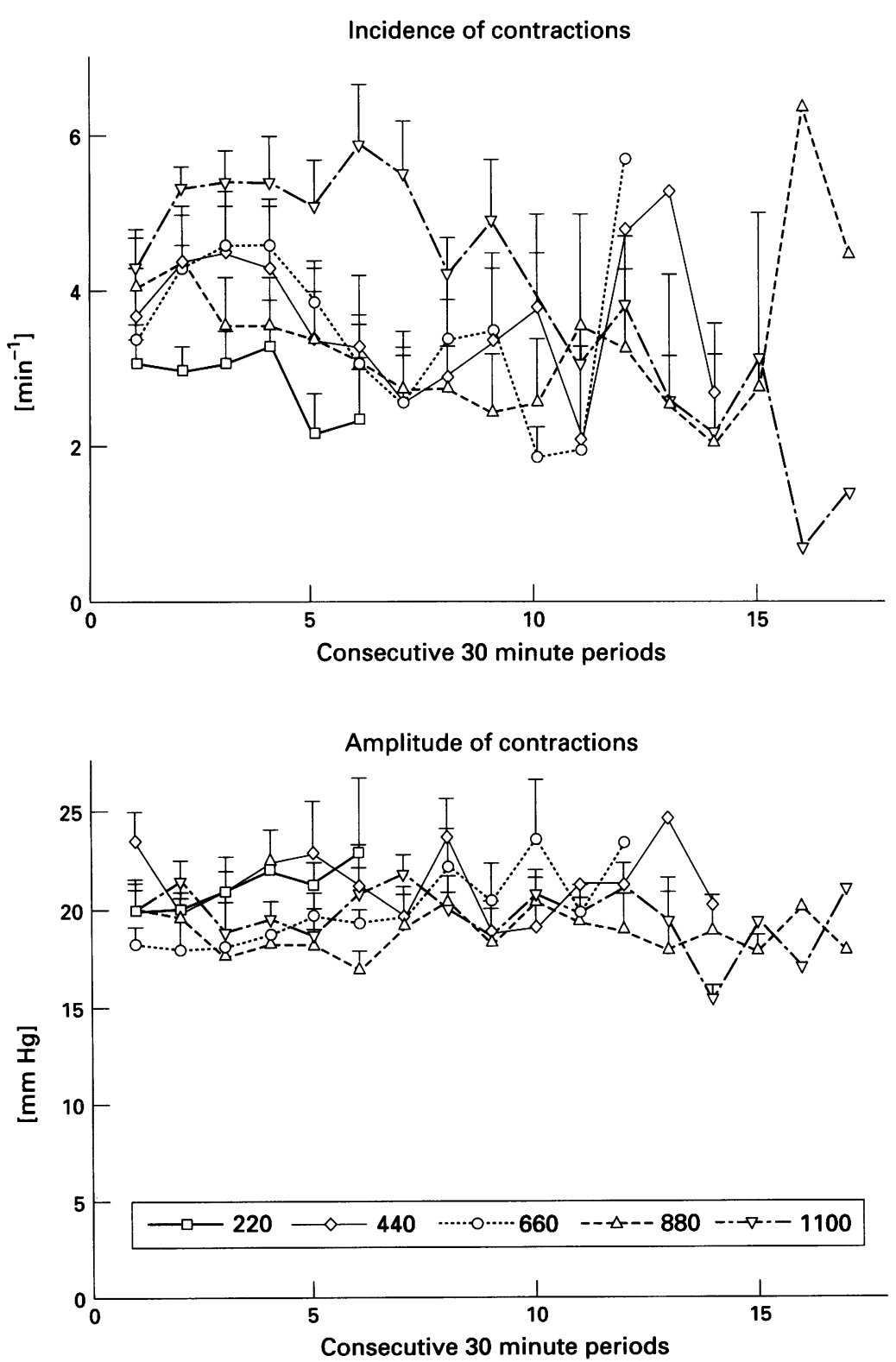

Figure 3: Mean incidence and amplitude of contractions in consecutive 30 minute periods after ingestion of one to five portions of a solid meal (220 kcal to $1100 \mathrm{kcal})$ during daytime.
DURATION OF POSTPRANDIAL MOTILITY

\section{Daytime}

Apart from two versus three portions ( $440 \mathrm{kcal}$ $v 660 \mathrm{kcal})$, postprandial motor activity was significantly prolonged by each $220 \mathrm{kcal}$ increase in the caloric load (Fig 1). The two volunteers who were unable to eat a $1100 \mathrm{kcal}$ meal for lunch were those within the group of volunteers who had the longest fed activity with the $880 \mathrm{kcal}$ meal.

\section{Night time}

Postprandial motor activity after feeding persisted significantly longer after ingestion of four portions of the pasta meal $(880 \mathrm{kcal})$ than after two portions ( $440 \mathrm{kcal})$. Duration of fed activity after dinner was not affected by the caloric value of the lunch ingested 10 hours earlier (Table II).

Daytime versus night time

Duration of fed activity after two or four portions of the pasta meal $(440 \mathrm{kcal}$ and 880 kcal) was not significantly different between day and night (Fig 2).

\section{INCIDENCE OF CONTRACTIONS}

\section{Daytime}

Mean incidence of contractions was significantly lower after the $220 \mathrm{kcal}$ than after the $1100 \mathrm{kcal}$ meal. The differences between all other meals for lunch were small and not significant (Table II). Figure 3 shows the mean incidence of contractions in consecutive 30 minute periods.

\section{Night time}

Mean incidence of contractions was not significantly different between the $440 \mathrm{kcal}$ and the $880 \mathrm{kcal}$ meals (Table II). Mean incidence of contractions in consecutive 30 minute periods gradually decreased over time (Fig 4).

\section{Daytime versus night time}

Incidence of contractions was not significantly different between daytime and night time meals. This was true for mean incidence of contractions during the total postprandial period and for consecutive 30 minute periods.

AMPLITUDE OF CONTRACTIONS

Mean amplitude of contractions during the postprandial period was not affected by meal size or meal timing. Likewise, mean amplitude of contractions was similar in consecutive 30 minutes periods of the postprandial state (Table II; Figs 3 and 4).

AREA UNDER THE CURVE (MOTILITY INDEX) As amplitude of contractions was uniform with all meals, mean area under the curve (AUC) closely reflected changes in the incidence of 
Incidence of contractions
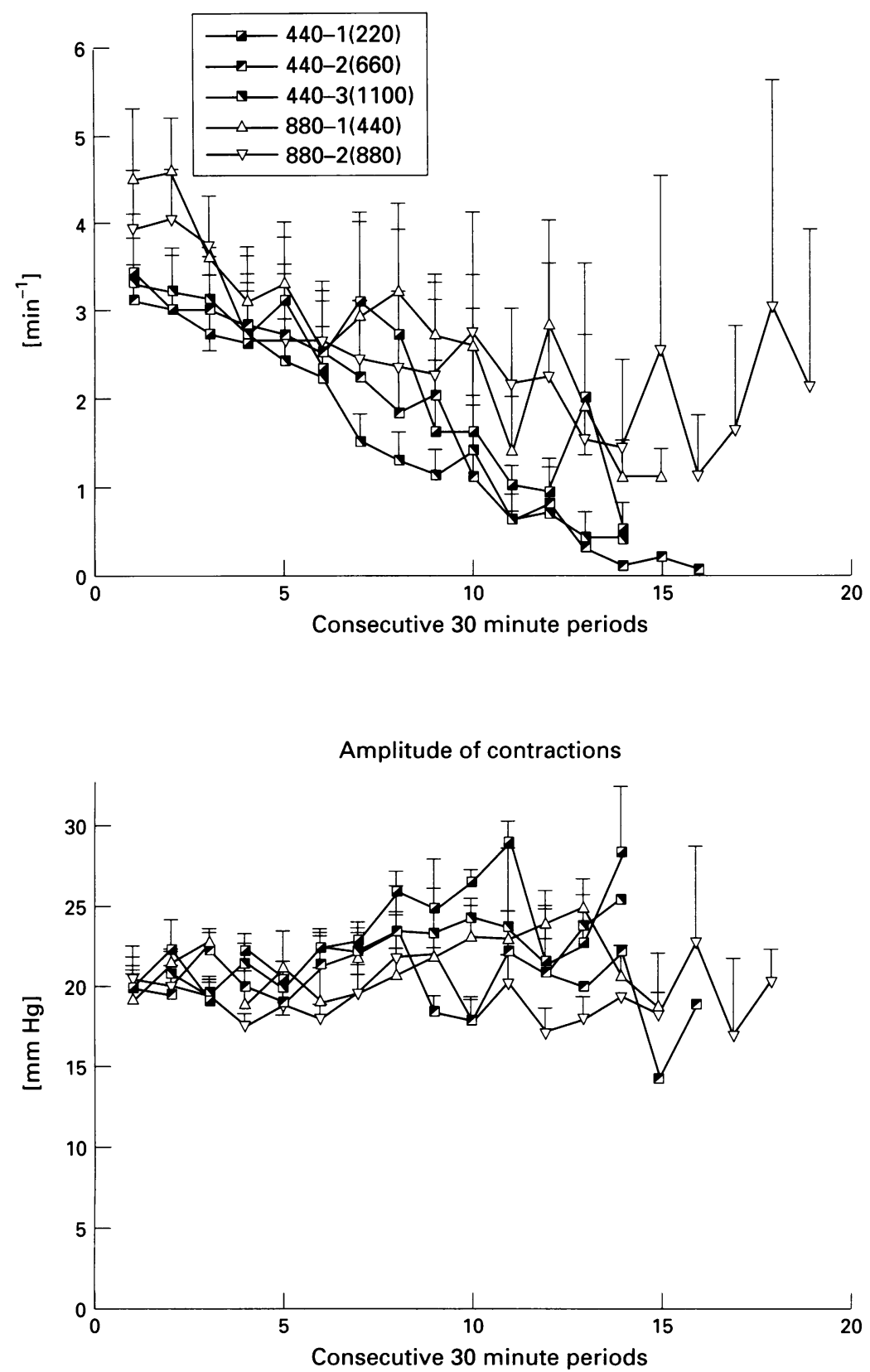

Figure 4: Mean incidence and amplitude of contractions in consecutive 30 minute periods after ingestion of two or four portions of a pasta meal ( $440 \mathrm{kcal}$ or $880 \mathrm{kcal})$ during night time. Two portions were eaten three times (10 hours after the $220 \mathrm{kcal}, 660 \mathrm{kcal}$, and 1100 kcal meals for lunch), four portions were eaten twice (10 hours after the 440 kcal and the 880 kcal meals or lunch). of a meal. This hypothesis was based on the findings of two recent studies with humans. Ouyang et al, in a controlled laboratory study, found a longer posprandial pattern when they increased the caloric load from $150 \mathrm{kcal}$ to 300 $\mathrm{kcal}$, whereas $600 \mathrm{kcal}$ failed to prolong the duration of the postprandial pattern further. ${ }^{5}$ In addition, Soffer and Adrian were unable to show a longer duration of fed activity after an $800 \mathrm{kcal}$ meal compared with a $400 \mathrm{kcal} \mathrm{meal.}{ }^{7}$ In the last study, volunteers were ambulatory, although they reported to the research centre for meals. The recording equipment used by Soffer and Adrian was identical to ours.

However, the present study, covering a wide range of calories, does not provide evidence for such a caloric ceiling. Instead, we found a significantly longer postprandial interval with almost every $220 \mathrm{kcal}$ increase in the caloric load of a meal. Thus, at least for the physiological caloric range, there is no maximum duration of the postprandial interval in the human small bowel. Actually, it would be difficult to test meals with an even higher caloric value, as in our study already two of the young, healthy, male volunteers were unable to cope with the $1100 \mathrm{kcal}$ meal.

Possibly, the longer postprandial pattern after high caloric meals reflects differences in gastric emptying rather than intrinsic effects within the small bowel. Due to the ambulatory nature of our study, we could not measure gastric emptying, but a $1100 \mathrm{kcal}$ meal will empty from the stomach far more slowly than a 220 kcal meal. ${ }^{13}$ Gastric emptying, in turn, has been shown to affect duration of postprandial motility. ${ }^{14-16}$ This is consistent with preliminary results from another study from our group. Addition of guar gum to nutrient meals, which is known to increase chyme viscosity and to slow gastric emptying, ${ }^{17-18} \mathrm{con}$ siderably increased duration of postprandial motility in the human small bowel. ${ }^{19}$

The effect of caloric load on incidence of contractions was far less pronounced. Incidence of contractions was only significantly different between the two extremes tested: 220 $\mathrm{kcal}$ and $1100 \mathrm{kcal}$. Thus, only drastic increases in the caloric value of a meal led to a significant increase in contractile activity. This is probably why Ouyang et al and our own group have previously been unable to show the same phenomenon with smaller differences in the caloric load of the meals compared. ${ }^{56}$ But our finding is consistent with a report from Stacher et al. ${ }^{20}$ For the purpose of our work, however, that study is difficult to interpret because Stacher et al compared a $1000 \mathrm{~kJ} / 24 \%$ fat meal with a $4200 \mathrm{~kJ} / 55 \%$ fat meal. A previous study from our group, however, suggested that chemical composition of liquid meals does not affect postprandial motility. ${ }^{6}$

It is also interesting to note that incidence of contractions after a meal gradually decreased over time. This was particularly obvious for the late night meals. This finding is consistent with a report from Ouyang et al, who found a progressive decrease in the motility index over the postprandial period. ${ }^{5}$ It seems that enteric receptors will be stimulated to a greater degree 
immediately after ingestion of a meal, thereby augmenting reflex peristaltic activity, than towards the end of the postprandial pattern, when particulate material will be more or less emptied from the small bowel.

Amplitude of contractions, however, was a very robust phenomenon in the postprandial period. Mean amplitude of contractions was not different between any of the five meals for lunch. Likewise, amplitude of contractions did not change within the postprandial period. With amplitude of contractions remaining constant, it is not surprising that the composite value - area under the curve - closely reflected the incidence of contractions. Thus, mean area under the curve was significantly different only between the $220 \mathrm{kcal}$ and the $1100 \mathrm{kcal}$ meals, and mean area under the curve progressively decreased within the postprandial period.

Neural input of the central nervous system clearly affects interdigestive motor activity of the small bowel. ${ }^{2122}$ Previous work from our group showed that the migrating motor complex cycle is shorter and phase II is virtually absent during sleep. ${ }^{22}$ For postprandial activity, Kumar et al have also shown a shorter postprandial interval during sleep. ${ }^{23}$ This disagrees with the findings presented here, which are based on the analysis of 40 rather than eight late night meals. The discrepancies between the studies, which used very similar recording equipment, are difficult to explain. The study protocols were different as we tested two meals on the same day, whereas Kumar et al tested three meals in two days. Also, in our study volunteers were given identical meals rather than offered a choice of menus with fixed proportions of nutrients. Finally, our volunteers were not allowed low calorie drinks, tea, or coffee between meals. In both studies, the interval between the midday and the late meal was 10 hours. In neither of these studies EEG activity was recorded simultaneously with activity of the small bowel, which would have provided evidence for the fact that volunteers actually slept after their late night meal.

In our study both duration of postprandial activity and contractile activity during that period were not different between daytime and night time. This was true for mean incidence and amplitude of contractions during the total postprandial period and for consecutive 30 minute periods within the postprandial interval. Thus, postprandial motor activity in the human small bowel is similar between daytime and night time.

1 Gill RC, Kellow JE, Browning C, Wingate DL. The use of intraluminal strain gauges for recording ambulant small bowel motility. Am $\mathscr{F}$ Physiol 1990; 258: G610-5.

2 Benson MJ, Castillo FD, Wingate DL, Demetrakopoulos J, Spyrou NM. The computer as referee in the analysis of human small bowel motility. Am $\mathcal{F}$ Physiol 1993; 264: G645-54.

3 SchangJC, Dauchel J, Sava P, Angel F, Bouchet P, Lambert A, Grenier JF. Specific effects of different food components on intestinal motility. Electromyographic study in dogs. Eur Surg Res 1978; 10: 425-32.

4 de Wever I, Eeckhout C, Vantrappen G, Hellemans J. Disruptive effect of test meals on interdigestive motor
Dever I, complex in dogs. Am $\mathcal{F}$ Physiol 1978; 235: E661-5.

5 Ouyang A, Sunshine AG, Reynolds JC. Caloric content of a meal affects duration but not contractile pattern of duodenal motility in man. Dig Dis Sci 1989; 34: 528-36.

6 v Schönfeld J, Evans DF, Wingate DL. Chemically different, but equicaloric nutrient liquids elicit a similar motor response in the human small bowel of ambulatory subjects [abstract]. Gastroenterology 1993; 104: A596.

7 Soffer EE, Adrian TE. Effect of meal composition and sham feeding on duodenojejunal motility in humans. Dig Dis $\mathrm{Sci}$ 1992; 37: 1009-114.

8 Hall KE, El-Sharkawy TY, Diamant NE. Vagal control of canine postprandial upper gastrointestinal motility. $A m \mathcal{f}$ Physiol 1986; 250: G501-10.

9 Jebbink RJ, Vanberge-Henegouwen GP, Akkermans LM, Smout AJ. Antroduodenal manometry: 24-hour ambulatory monitoring versus short-term stationary manometry in patients with functional dyspepsia. Eur $\mathcal{F}$ Gastroenterol Hepatol 1995; 7: 109-16.

10 v Schönfeld J, Evans DF, Wingate DL. The effect of barium sulphate on small bowel motility in man. Eur $\mathcal{f}$ Gastroenterol Hepatol 1995; 7: 877-80.

11 Sarna SK. Cyclic motor activity; migrating motor complex: 1985. Gastroenterology 1985; 89: 894-913.

12 Ehrlein HJ, Schmid HR, Feinle C. Characteristic motor patterns of phase II and behaviour of phase III in the fed state. $\mathcal{F}$ Gastrointest Motil 1992; 4: 317-27.

13 McHugh PR, Moran TH. Calories and gastric emptying: a regulatory capacity with implications for feeding. $A m \mathcal{F}$ Physiol 1979; 236: R254-60.

14 Madsen JL, Dahl K. Human migrating myoelectric complex in relation to gastrointestinal transit of a meal. Gut 1990; 31: $1003-5$.

15 Kerlin P, Phillips S. Variability of motility of the ileum and jejunum in healthy humans. Gastroenterology 1982; 82: 694-700.

16 Read NW, Al-Janabi MN, Edwards CA, Barber DC. Relationship between postprandial motor activity in the human small intestine and the gastrointestinal transit of food. Gastroenterology 1984; 86: 721-7.

17 Meyer JH, Gu Y, ElashoffJ, Reedy T, Dressman J, Amidon G. Effects of viscosity and fluid outflow on postcibal gastric emptying of solids. Am $\mathcal{F}$ Physiol 1986; 250: G161-4.

18 MeyerJH, Elashoff, Porter-Fink V, DressmanJ, Amidon GL Human postprandial gastric emptying of 1-3 millimeter Human postprandial gastric emptying of 1-3
spheres. Gastroenterology 1988; 94: 1315-25.

19 v Schönfeld J, Evans DF, Wingate DL. Guar gum prolongs duration of postprandial motility pattern in the human small bowel [abstract]. Gastroenterology 1993; 104: A596.

20 Stacher G, Gaupmann G, Steinringer H, Schneider C, Stacher-Janotta G, Steiner-Mittelbach G, Abatzi TA. Effects of cisapride on postcibal jejunal motor activity. Dig Dis Sci 1989; 34: 1405-10.

21 Valori RM, Kumar D, Wingate DL. Effects of different types of stress and of "prokinetic" drugs on the control of the fasting motor complex in humans. Gastroenterology 1986; 90: 1890-900.

22 Kumar D, Idzikowski C, Wingate DL, Soffer EE, Thompson P, Siderfin C. Relationship between enteric migrating motor complex and the sleep cycle. $A m \mathcal{f}$ migrating motor complex

23 Kumar D, Soffer EE, Wingate DL, Britto J, Das-Gupta A, Mridha K. Modulation of the duration of human postprandial motor activity by sleep. Am $\mathcal{F}$ Physiol 1989 ; 256: G851-5. 